\title{
ANIMAIS VIVOS, FEIRA LIVRE
}

\author{
Live animals, free fair
}

Lucas Barreto de Souza ${ }^{1}$

\begin{abstract}
http://dx.doi.org/10.52641/cadcaj.v7i1.660
\end{abstract}
RESUMO: Neste artigo, trato de debater, a partir de uma inspiração etnográfica oriunda de uma visita a um setor de animais vivos de uma grande feira livre baiana, a Feira de São Joaquim (anteriormente chamada de Feira de Água de Meninos), aspectos relacionados às epistemologias ecológicas, à TAR (teoria do ator-rede), a agência dos objetos, relações humano-animal, mercados úmidos, biossegurança e sacrifício animal. Adoto a premissa de Latour (1999) de que a ação não é propriedade, exclusivamente, de humanos, mas de uma associação de atuantes. Tendo considerado previamente também o poder de agência dos objetos, conforme Gell (1998), proponho voltar as atenções, desta vez, aos animais não-humanos, mais do que aos objetos, ainda de uma perspectiva da indissociabilidade entre conhecimento e percepção/ experiência, constatada através da imersão na matéria e no mundo/ engajamento contínuo no ambiente. A discussão está articulada a diversos referenciais bibliográficos, mas a condução do raciocínio está pautada em diálogos com alguns argumentos e exemplos apresentados pelo autor Caetano Sordi em seus artigos.

Palavras-Chave: biossegurança, epistemologias ecológicas, relações humano-animal.

\begin{abstract}
In this article, I try to debate, from an ethnographic inspiration coming from a visit to a live animal sector of a large free fair in Bahia, the Feira de São Joaquim (previously called Feira de Água de Meninos), aspects related to epistemology ecological, to TAR (actornetwork theory), the agency of objects, human-animal relationships, wet marks, biosafety and animal sacrifice. I adopt Latour's (1999) premise that action is not the property of humans, but of an association of actors. Also considering the power of agency of objects, as Gell (1998), in a previous moment, I propose to turn attention, this time, to non-human animals, more than to objects, still from a perspective of the inseparability between knowledge and perception/ experience, verified through the immersion in the matter and in the world, of the continuous engagement in the environment. The discussion is linked to several bibliographic references, but the reasoning is based on debates with the arguments presented by the author Caetano Sordi in some of his articles.
\end{abstract}

Keywords: biosecurity, ecological epistemologies, human-animal relationships.

\footnotetext{
${ }^{1}$ Graduado e mestre em antropologia pela Universidade Federal da Bahia, doutorando em Antropologia Social pela Universidade Federal do Rio Grande do Sul - Bolsista Capes.
} 


\section{PALAVRAS INICIAIS}

Trato, neste artigo, de debater, a partir de uma inspiração etnográfica oriunda de uma visita a um setor de animais vivos de uma grande feira livre baiana, a Feira de São Joaquim (anteriormente chamada de Feira de Água de Meninos), aspectos relacionados às epistemologias ecológicas, à TAR (teoria do ator-rede), a agência dos objetos, relações humano-animal, marcados úmidos, biossegurança e sacrifício animal. O evento etnográfico, a visita, tem precedentes em diversas outras visitas anteriores à feira, em função da realização de pesquisa de campo; o recorte temático, entretanto, era outro - a ênfase estava também na relação humano - não humano, porém voltada a analisar a vida social dos artefatos de palha no espaço da feira, a observar a ação técnica, a eficiência técnica sobre a matéria. Em acordo com a premissa de que o ambiente seja o lugar efetivo, discordo da ideia de externalidade do observador em relação ao objeto pesquisado, e logo apresento pistas para a consideração de uma subjetivação do ambiente. Adoto a premissa de Latour (1999) de que a ação não é propriedade de humanos, mas de uma associação de atuantes. Considerando também o poder de agência dos objetos, conforme Gell (1998), em momento prévio, proponho voltar as atenções, desta vez, aos animais não-humanos, mais do que aos objetos, ainda de uma perspectiva da indissociabilidade entre conhecimento e percepção/ experiência, constatada através da imersão na matéria e no mundo, do engajamento contínuo no ambiente.

\section{LEITURAS}

O primeiro impacto, ao iniciar a leitura de Mobilização e predação: a guerra contra espécies invasoras em duas perspectivas, escrito por Caetano Sordi, foi de estranhamento. Um estranhamento que talvez se assemelhe às reações despertadas em alguns espectadores do filme etnográfico Os mestres loucos (Rouch, 1950), pensando a partir dos comentários posteriores sobre as próprias impressões..

O choque provocado neles talvez estivesse mais próximo do espanto sentido pelos telespectadores do programa culinário de TV a cabo que assistiram ao abate/ sacrifício de um cordeiro, caso polêmico mencionado no artigo Criação animal, ideologia zootécnica e contrato domesticário. Creio ter sentido desconforto proporcional, ou semelhante, ao iniciar a leitura de 
Mobilização e predação - a impressão que tive foi de que o porte e uso de armas de fogo é algo recorrente, que não produz grande estranhamento, por si mesmo e em geral, no estado do Rio Grande do Sul, ou pelo menos, em sua parte rural.

Pode ter sido uma impressão errônea, mas de todo modo a maneira minuciosa como o autor especificou tipos de armas, a partir dos calibres, detalhes relativos à legislação e informações oficiais de divisões do estado brasileiro induziram-me a pensar no objeto "arma", o que me fez remeter o pensamento a teorias sociais que consideram e enfatizam a agência dos objetos, especialmente na figura de três autores: Clifford Geertz, Bruno Latour e Alfred Gell.

Menos o primeiro e o terceiro, dado que seus livros (ou capítulos) que me vieram à memória nesse contexto foram mais ligados ao campo da arte, de processos interacionais envolvendo pessoas e coisas em contextos artísticos: o capítulo Arte como sistema cultural, do livro O saber local: novos ensaios de antropologia interpretativa (Geertz, 2012), e Art and agency (Gell, 1998). Gell (1998) enfatiza o poder de agência dos objetos; Geertz (2012) refere-se a objetos estéticos que "exigem que os assimilemos": "não podemos deixar que o confronto com objetos estéticos flutue, opaco e hermético, fora do curso normal da vida social" (Geertz, 2012: 100).

O exemplo usado por Latour, de que me recordei, apresentado em $A$ esperança de Pandora (2001), este sim está mais ligado à questão dos revólveres e outras armas e ao armamentismo, ou anti-armamentismo, a esta questão de modo amplo. O autor coloca que National rifle association lançou o lema "Armas não matam pessoas". E que uma campanha anti-armamentista, em acordo com uma visão materialista, produziu, em contraponto, o slogan: "armas matam pessoas"; Latour considera que "todo artefato tem seu script, seu potencial para agarrar os passantes e obrigá-los a desempenhar um papel em sua história" (2001: 203-204).

A dúvida que permanecia em meu pensamento enquanto lia o artigo de Sordi era: ainda que se considere a destreza e periculosidade do animal, que parece constituir uma verdadeira ameaça a lavouras e outros animais (e um objeto de cobiça, almejado por praticantes de caça esportiva, por outro lado), a única maneira de enfrentamento do javali selvagem é por meio do uso de armas de fogo?

A anedota do abate (televisionado) do cordeiro, por outro lado, apresenta um episódio de midiatização de um procedimento técnico que não é litúrgico religioso, de modo que, aproximase discretamente da seara cinematográfica, por haver registro fílmico/ gravação, embora o tipo (e a finalidade) do abate sejam deveras distintos. A esfera de abate de animais asselvajados representa ainda outra modalidade. No espaço que visitei em busca por inspiração para a escrita 
deste artigo, um setor de animais vivos em uma grande feira livre, na Bahia, presencia-se os animais em momento anterior ao do abate. Aqui, trata-se, em parte considerável dos casos, de animais que serão sacrificados ritualísticamente, segundo preceitos e normativas estritas, específicas, mas com certo grau de variabilidade, a depender da religião - de modo geral, no campo das religiões de matriz africana.

Cais da Feira de São Joaquim, 2021. Lucas Souza.

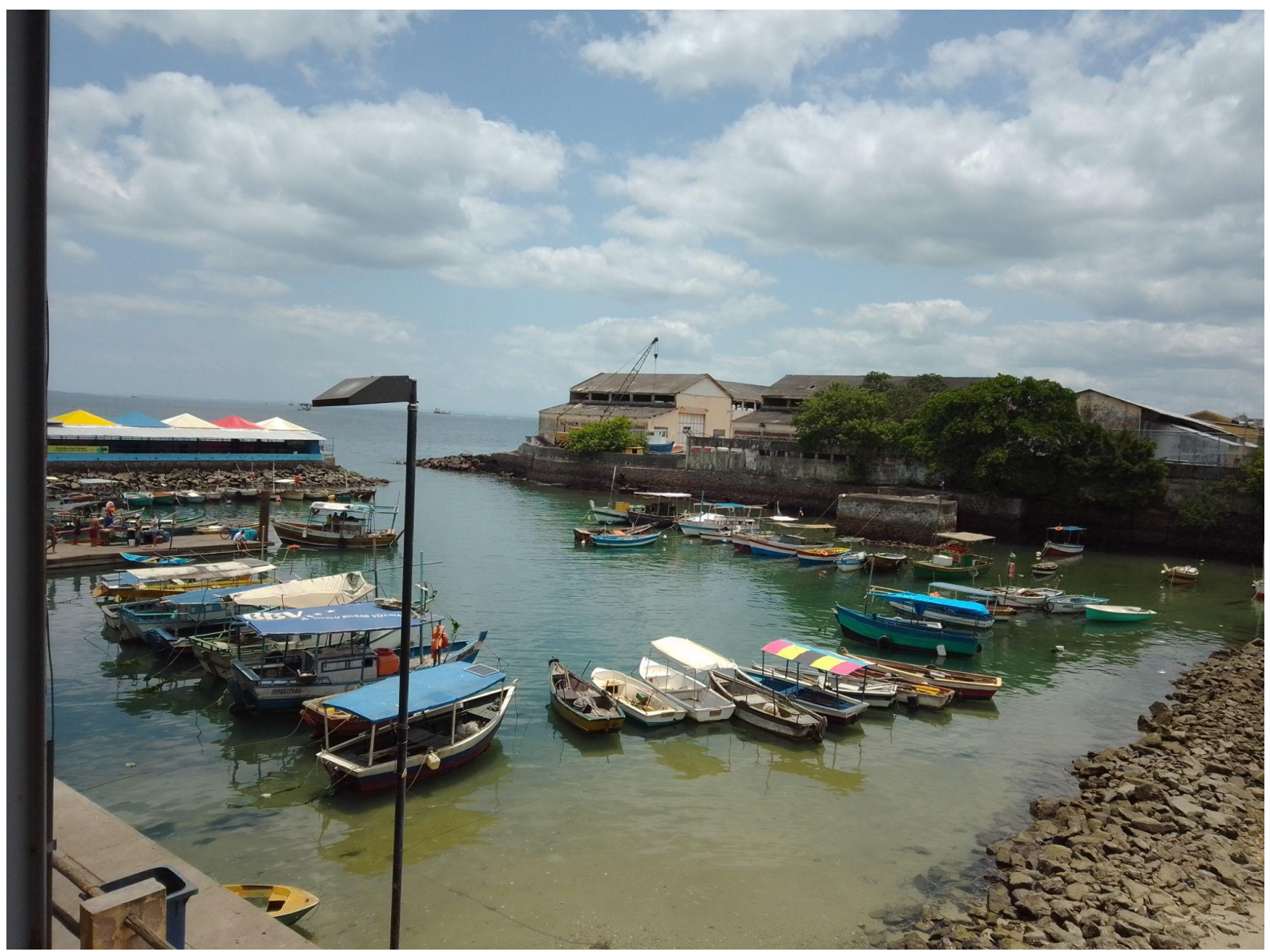

O artigo de Sordi, publicado em 2020, é estruturado de uma maneira que possibilita que a complexidade de suas correlações, costuras, conexões teóricas, reflexivas, etnográficas, esteja mais acessível a não especialistas: pressupostos teóricos; pressupostos metodológicos; estruturação argumentativa; explorações etnográficas; alinhamento propositivo aplicacional (nesse caso, assinalando Lévi-Strauss e Márcio Goldman como referências).

O pressuposto teórico básico é da existência de uma multiplicidade de definições para a ideia de guerra e a relação com a alteridade em diferentes contextos. O pressuposto metodológico 
de Sordi, nesse artigo, encontra inspiração na antropologia simétrica, Goldman e Latour, e em reflexões de Lévi-Strauss sobre o canibalismo e a devoração como alteridade perigosa, ao passo que busca tratar as potencialidades do pensamento ameríndio com vistas à análise de impasses biopolíticos modernos de um ponto de vista outro, incluídas questões postas pela antropologia da biossegurança contemporânea.

As duas perspectivas apontadas são relacionadas a modalidades de predação: uma, de combate, enfrentamento, exclusão, afastamento, ligada a estratégias de guerra, direito a autodefesa, extermínio, proteção de lavouras e de si mesmo; outra, ligada ao fortalecimento através da incorporação (devoração), com suporte em reflexões sobre o canibalismo, contribuições de Lévi-Strauss.

Então, resgata historicamente a moderna biologia das invasões e as "explosões biológicas", passando pela consolidação da biodiversidade, nas décadas de 1970 e 1980, considerada principal valor do discurso ambiental. Relata também as ameaças: ação direta do ser humano sobre o ambiente natural; identificação das espécies exóticas como invasoras. Culmina, nesta etapa, em uma dicotomia ou conflito: a necessidade de conter a invasão biológica, por um lado, e a ideologia global de conectividade e livre comércio, por outro, contrapostas. Aborda componentes geopolíticos e econômicos do problema da invasão biológica; trata do homogeoceno, modo como a biologia nomeia possivelmente o mesmo período que em antropologia se conhece como antropoceno. O autor nota duas modalidades de críticas à biologia das invasões: oposição científica e acusações de xenofobia implícita na utilização de determinados termos e expressões metafóricas nesse âmbito.

Para Segata e Mastrangelo (2020), "biossegurança” é um termo elástico que designa um conjunto de ações e de instruções voltadas à "contenção de riscos inerentes à exposição a agentes biológicos potencialmente contaminantes" (p. 8). Inicialmente, o protagonismo nos debates nesse campo era dos ambientes de atuação da biotecnologia; a expressão biossegurança tornou-se mais robusta na década de 1970. A disseminação de vírus e outros agentes patógenos, através do comércio de mercadorias, circulação de pessoas e trânsito de pessoas como produto de comércio, costumeiramente tem servido como base explicativa para os processos de tomada de contorno de pandemias.

Em momentos críticos como esses, a morte, muitas vezes, não era resultante da doença propriamente, mas da fome ou da intoxicação pelo consumo de insumo que teriam perecido. As estruturas de desigualdade ficam ainda mais aparentes do que em outros períodos. Essas 
estruturas "favorecem a proteção à parcela da população, especialmente das camadas médias e altas, que tem condições de se manter em isolamento, com acesso remoto ao trabalho, à escola e a inúmeros serviços por meio de aplicativos, além da ampliada segurança de acesso a leitos hospitalares garantidos por planos privados de saúde" (Segata; Mastrangelo, 2020, p. 10), por um lado; por outro, enredam uma parcela da população regularmente exposta a riscos e à morte, "sejam eles decorrentes das históricas cargas acumuladas de vulnerabilidade, como a pobreza, o racismo e a falta de acesso a direitos fundamentais, como também pela cada vez mais crescente precarização de suas relações de trabalho" (Ibidem).

\section{OBSERVAÇÕES E OUTRAS LEITURAS}

Os trabalhadores da Feira de São Joaquim, em Salvador, encontram-se nesta parcela da população. É possível que a Feira não tenha fechado nem mesmo nos períodos de confinamento mais restritivos - tendo sido referenciada na imprensa baiana como local de aglomeração, que desse modo apresentaria riscos de transmissão do vírus. Mesmo com medidas sanitárias protocolares adotadas, a feira funcionou, de domingo a domingo, ao longo dos meses de maiores restrições, com a política de lockdown. Estamos diante de um exemplo do escancaramento das estruturas de desigualdade. Além disso, quiçá influenciada pela versão de acordo com a qual o mercado de Wuhan, na China, estaria associado ao boom da propagação do vírus, a imprensa local de Salvador manteve o hábito de "taxar a pobreza" com seus métodos sensacionalistas, ao mesmo tempo em que outros eventos com aglomerações aconteciam, embora não fossem evidenciados. Nesse ponto, há mesmo um elo semântico entre o famoso mercado chinês e a grande feira baiana: ambos são mercados úmidos. As espécies animais comercializadas variam entre os lugares, mas ambas possuem grandes áreas, com espécies animais expostas para consumo humano. Na feira baiana, existe o setor das carnes, aberto, na parte central, no miolo da feira; separado de um especificamente voltado aos mariscos e peixes; ao lado de um galpão exclusivamente destinado aos animais vivos.

A feira de São Joaquim está situada em Salvador, na cidade baixa, mais especificamente na Avenida Engenheiro Oscar Pontes, entre a estação da barca férrea e um cais, na enseada de São Joaquim. Possui extensão territorial estimada de 35 a 38 mil metros quadrados ${ }^{2}$. Estima-se ainda

\footnotetext{
${ }^{2}$ De acordo com a CONDER (Companhia de Desenvolvimento Urbano do Estado da Bahia), são 36595 mil metros quadrados; algumas fontes atribuíram dimensão maior.
} 
que, em média, de 20 a 30 mil pessoas frequentam diariamente a feira, atendidos e servidos por 5 mil feirantes "fixos", mais 2 mil "circulantes", universo do qual $20 \%$ são mulheres, $80 \%$ são homens; $80 \%$ são negros e $75 \%$ tem mais de 50 anos de idade. Maioria de pretos e pardos, do sexo masculino e um alto percentual de idosos (dados do SINDIFEIRA - sindicato dos feirantes, fornecidos pelo ex-presidente Marcílio, também feirante, em entrevista realizada em janeiro de 2017).

Galináceos. 2021. Lucas Souza.

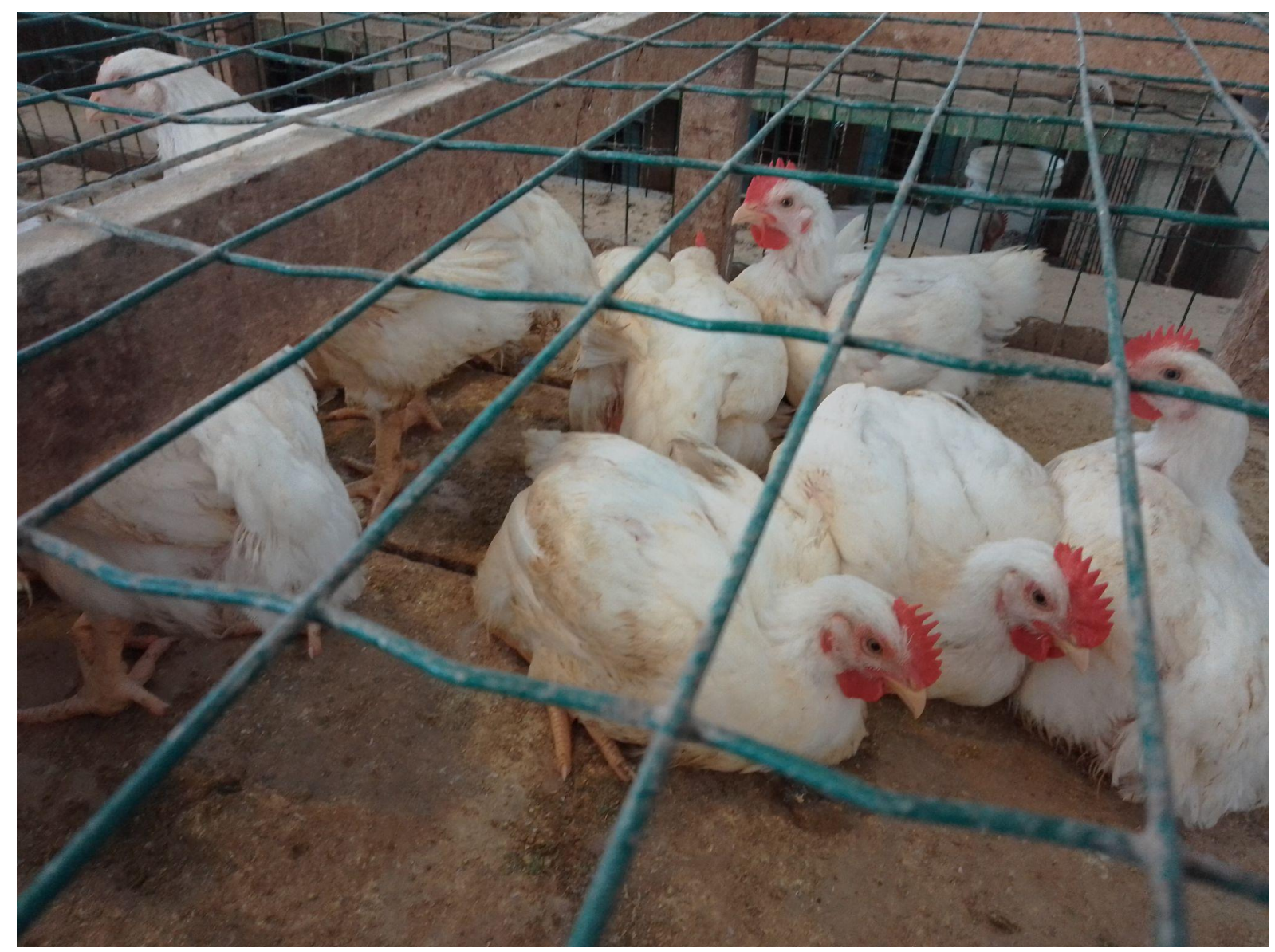

No artigo Criação animal, ideologia zootécnica e contrato domesticatório, Caetano Sordi (2019) discute as múltiplas leituras e conotações do conceito de domesticação na literatura antropológica e arqueológica, ao longo de várias décadas. A emergência das relações de propriedade e dominação, há dez mil anos, conforme Engels e Childe, situada na ocasião da "Revolução neolítica"; definições de arqueólogos interessados mais especificamente na relação entre cultura

\footnotetext{
${ }^{3}$ A categoria trabalhadores fixos abrange os feirantes que atuam nas pedras - estruturas de concreto, boxes, bancas e barracas, incluindo bares e restaurantes e a peixaria; a categoria circulantes engloba vendedores ambulantes, "carrinhos" - os carregadores, pessoal da limpeza, dentre outros que não trabalham em estruturas fixas.
} 
material, sociedade, economia, nos processos de dispersão e difusão de técnicas entre sociedades e culturas diferentes, que acreditam que a domesticação é um processo biológico e cultural que se dá quando animais domados são incorporados à estrutura social do grupo humano e se tornam objeto de relações de propriedade; a fusão realizada por Nilbert entre os conceitos de "domesticação" e "dessacralização", resultante em domedesacration, que importa para as ciências sociais o argumento deontológico em favor dos direitos dos animais; Sigaut, que apresenta três aspectos semânticos que compõem o conceito de domesticação - jurídico, zootécnico e etológico. Segundo Sordi, Ingold retoma ideias de autores anteriores e conclui que a passagem de uma economia de coleta e caça para outra pastoril coincidiria com modos de engajamento baseados em simetria ontológica e confiança ou assimetria e dominação.

Engaioladas, 2021 Lucas Souza.

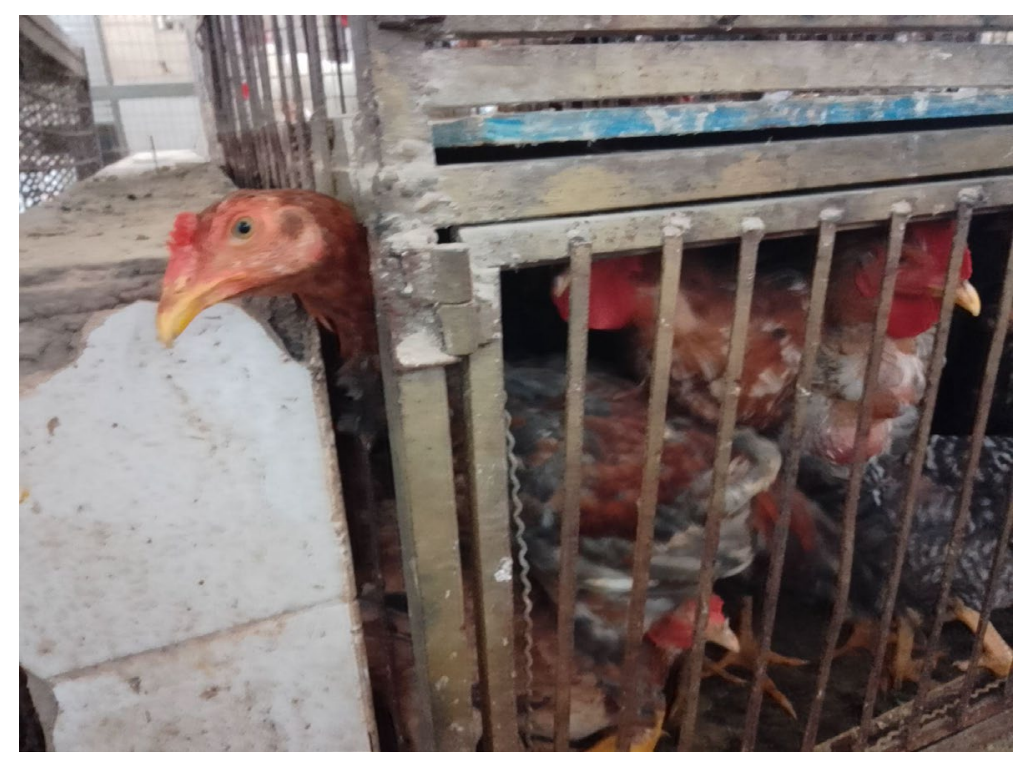

Após, apontar alguns outros pontos destacados por Ingold, e desdobrá-los, em outra etapa do mesmo artigo, Sordi pontua a "ideologia zootécnica" enquanto corporificada por agentes públicos e privados que pregam o fim da vinculação da criação de ovelhas com a subsistência, com vistas a sua profissionalização como negócio. Critica, de um lado, a ideologia zootécnica e as engrenagens nas quais opera, e, por outro, movimentos de libertação animal, ao menos parcialmente.

Bode, 2021. Lucas Souza. 


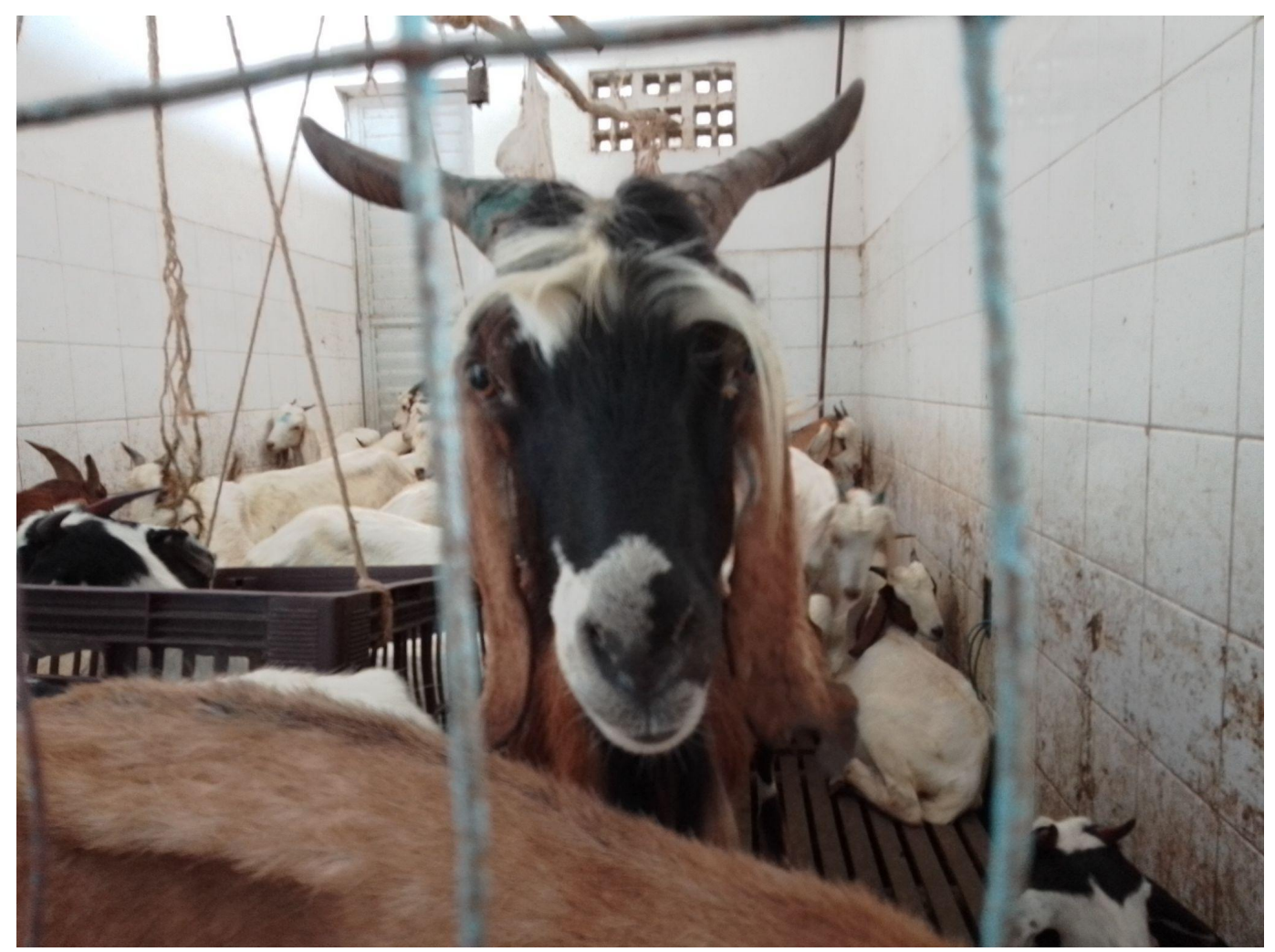

Nos movimentos animalistas, libertação animal (abolicionismo) e protecionismo, parte dos adeptos reproduz preconceitos de origem e classe ao reificar a condição de subalternidade de coletivos humanos já vitimados pela ideologia zootécnica, do mesmo modo que os animais seus companheiros de trabalho; isto ocorreria ao passo que "os agentes que utilizam animais para fins econômicos em uma mesma (ampla e abstrata) categoria e ao subsumirem a variedade histórica, cultural e geográfica dos sistemas domesticatórios a uma grande narrativa escatológica”, adotam essa postura de reafirmação da condição de subalternidade de certos coletivos (Sordi, 2019). Um grupo que se sente marginalizado e pressionado dentro do sistema agropecuário vê, na atitude de um estrato urbano que se entende progressista, uma espécie de continuação dessa marginalização.

No caso das religiões de matriz africana, em particular, o contraste entre a morte vazia de significado dos abatedouros industriais, de um lado, e a significância cultural do ritual sacrificial, de outro, é frequentemente apontada como argumento pelos seus agentes que denunciam o animalismo como uma modalidade de colonialismo seletivista.

“(...) em suas tentativas esporádicas de proibição de sacrifício religioso, o animalismo, que em geral se identifica com pautas da esquerda contracultural, acabe estabelecendo alianças impensáveis de outro modo com setores mais conservadores da sociedade, haja visto o conflito religioso vigente no Brasil entre africanismo e determinadas denominações neopentecostais" (Sordi, 2019, p. 316). 
Paradoxalmente, na "defesa de uma animalidade abstrata, o animalismo rejeita e julga possível interromper o fato histórico e ecológico que mais nos aproxima moral e afetivamente dos animais: a domesticação; a constituição de uma morada com seres muito diferentes de nós" (p. 319).

\footnotetext{
"Herdeiro da tradição ascética e puritana de afastamento do mundo e alinhado a certo identitarismo intransigente e contemporâneo que se dissemina a passos largos em outras esferas do debate público contemporâneo, o discurso de libertação animal promete libertar-nos do fardo da predação sem, contudo, explicar como seria possível realizar essa proeza e contornar, ao mesmo tempo, a necessidade ecológica de controle populacional das espécies 'libertadas', muitas das quais, por milênios, tiveram no ser humano seu único predador" (Idem, p.325).
}

\section{CONSIDERAÇÕES FINAIS}

A recente (e breve) visita, antropologicamente interessada, ao setor de animais vivos da Feira de São Joaquim ocorreu no domingo (10 de outubro de 2021). Não havia maiores pretensões de sair com uma quantidade de dados tal qual permitem as etnografias de longa duração; o objetivo se aproximava mais de uma busca por inspiração para acessar o referencial bibliográfico encontrando exemplar correlato na realidade vivida pessoalmente, além do que está acessível através das palavras. Nesse passeio etnográfico pela feira, com os cuidados sanitários indicados, ao observar em minha frente animais enjaulados, em um mercado de animais vivos, vieram em reverberação memórias das leituras: as tantas reflexões sobre mercados úmidos, no bojo da questão da pandemia de sars-covid-19; a constatação de uma paisagem multiespécie, em local no qual os animais relacionam-se entre si, para além da interferência humana, mesmo considerando que eles estão naqueles gaiolas por ação humana, em um espaço antropizado e estruturado para fins de interesses humanos; a organização da feira, as interações; as relações humano-animal; higiene e biossegurança; as temáticas da predação e devoração, direitos dos animais, movimentos de libertação animal; sacrifício animal em contexto religioso; racismo e intolerância religiosa em contextos de perseguição a práticas religiosas de matriz africana. Então, 
como em flashes os assuntos sobre os quais trabalhamos em antropologia contemporânea surgiam em justaposição enquanto eu passeava o olhar por aquele espaço, a olhar nos olhos alguns daqueles animais cujo destino é o abate (para consumo) ou sacrifício religioso (oferenda ou consumo), observando penas ao vento, a sentir o forte odor principalmente das aves, em um galpão vizinho a um galpão destinado ao comércio de frutos de mar, que está localizado a alguns metros de um aglomerado de bancas de madeira com partes desmembradas de animais expostas, à venda, em uma manhã ensolarada de domingo à beira da enseada de São Joaquim, na cidade baixa, em Salvador-BA.

Acesso lateral ao setor de animais vivos, 2021. Lucas Souza.

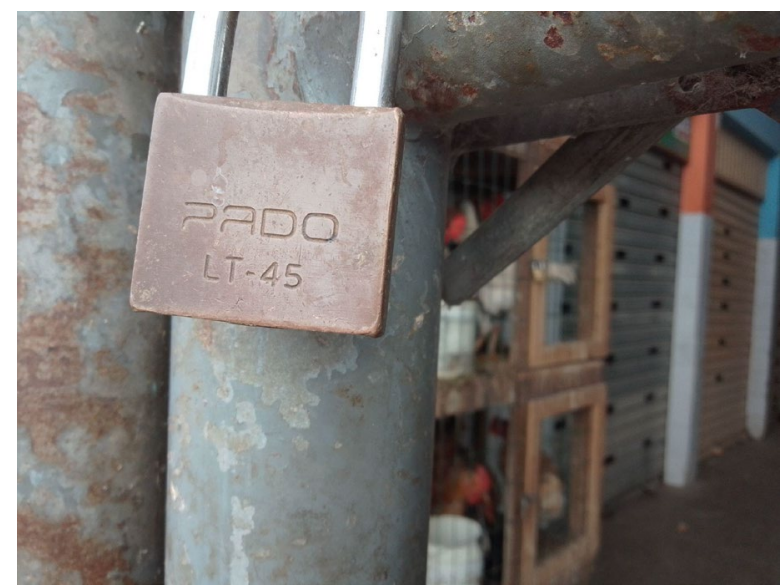

\section{REFERÊNCIAS BIBLIOGRÁFICAS}

APPADURAI, Arjun. Introdução: mercadorias e a politica de valor. In: A vida social das coisas. As mercadorias sob uma perspectiva cultural. APPADURAI, Arjun (org.). Niterói: Editora da Universidade Federal Fluminense. 2008 [1986].

BECKER, Howard. Problemas de Inferência e Provana Observação Participante. In: Métodos de pesquisa em Ciências Sociais. Cap. 2 São Paulo: Hucitec, 1994.

GELL, Alfred. Definição do problema: a necessidade de uma antropologia da arte. In: Art and agency. Oxford: Clarendon Press, 1998.

GEERTZ, Cliford. Arte como sistema cultural. In: __ O saber local: novos ensaios de antropologia interpretativa. 12 ed. Petrópolis, RJ: Vozes, 2012 (col. antropologia).

Uma descrição densa: por uma teoria interpretativa da cultura. A interpretação das culturas. Rio de Janeiro: Guanabara, 1989.

INGOLD, Trazendo as coisas de volta à vida: emaranhados criativos num mundo de materiais. In: Horizontes Antropológicos, ano 18, n. 37, p. 25-44. Jan./jun.. Porto Alegre, 2012.

Estar Vivo: ensaios sobre movimento, conhecimento e descrição. Tradução de Fábio Creder. Petrópolis, RJ: Vozes, 2015. - Col. Antropologia. 
KOPYTOFF, Igor. A biografia cultural das coisas: a mercantilização como processo. In: A vida social das coisas. As mercadorias sob uma perspectiva cultural. APPADURAI, Arjun (org.). Niterói: Editora da Universidade Federal Fluminense. 2008 [1986].

LATOUR, Bruno. Jamais Fomos Modernos: ensaio de sociologia simétrica. Tradução de Carlos Irineu da Costa. Rio de Janeiro: 34, 1994 [1991].

A esperança de pandora: ensaios sobre a realidade dos estudos científicos. Tradução de Gilson César Cardoso de Souza. Bauru, SP: Edusc, 2001.

Reagragando o social: uma introdução à teoria do ator-rede. Tradução de Gilson César Cardoso de Souza. Salvador: Edufba, 2012.

Onde aterrar? como se orientar politicamente no Antropoceno. Rio de Janeiro: Bazar Tempo, 2020.

LEWGOY, Bernardo; SORDI, Caetano. "O que pode um príon? O caso atípico de Vaca Louca no Brasil e seus desdobramentos. Anthropológicas, v. 24, n. 1, 2013, pp. 125-143.

SEGATA, Jean; MASTRANGELO, Andrea. As biosseguranças e suas antropologias. Horizontes Antropológicos, n. 57, p. 7-25, 2020.

SORDI, Caetano. 'Mobilização e predação: a guerra contra espécies invasoras sob duas perspectivas”. Horizontes Antropológicos, v. 26, n. 57, 2020. pp. 207-237.

SORDI, Caetano. "Bicho bandido: wild boars, biological invasions and landscape transformations on the Brazilian-Uruguayan border (Pampas region)". Social Anthropology/Anthropologie Sociale, 28, 3, 2020. pp. 614-628.

SORDI, Caetano. "Criação animal, ideologia zootécnica e contrato domesticatório". In: Luciano Félix Florit; Carlos Alberto Ciocce Sampaio; Arlindo Philippi Jr. (org.). Ética Socioambiental. Barueri: Manole, 2019. pp. 306-328.

STEIL, Carlos; CARVALHO, Isabel Cristina de Moura. Epistemologias ecológicas: delimitando um conceito. Rev. Mana, v. 20, n.1, p. 163-183. 2014.

TSING, Anna. "The Global Situation". In: Jonathan Xavier Inda \& Renato Rosaldo (eds). The Anthropology of Globalization. Malden, Blackwell, 2004, p. 453-485.

WOLF, Meike. Is there really such a thing as "One Health"? Thinking about a more than human world from the perspective of cultural anthropology. Social Science \& Medicine, v. 129, p. 5-11, 2015.

\section{FILMOGRAFIA}

A Grande Feira. Roberto Pires, 1961.

Água de Meninos: a Feira do Cinema Novo. Fabíola Aquino, 2012.

Arquiteturas: Feira de São Joaquim, Bahia. Paulo Markun; Sergio Roinzenblit, 2015.

Disponível em: https://www.youtube.com/watch?v=fEp6p5zRKm0 
Expedição Brasil Gastronômico 2013 - Feira de São Joaquim-Bahia. Rusty Marcellini, 2013. Disponível em: https://www.youtube.com/watch?v=fNPXIhjd040

Les maître fous. Jean Rouch, 1955. 
ANEXO I - Mapa do Galpão Água de Meninos (Galpão Provisório), onde funcionou por tempo determinado o setor de animais vivos, até a sua transposição para a Nova Feira de São Joaquim, em 2016, após um longo processo de reestruturação e mudanças.

ANIHAIS

\section{galpä́o á́ua de Meninos}

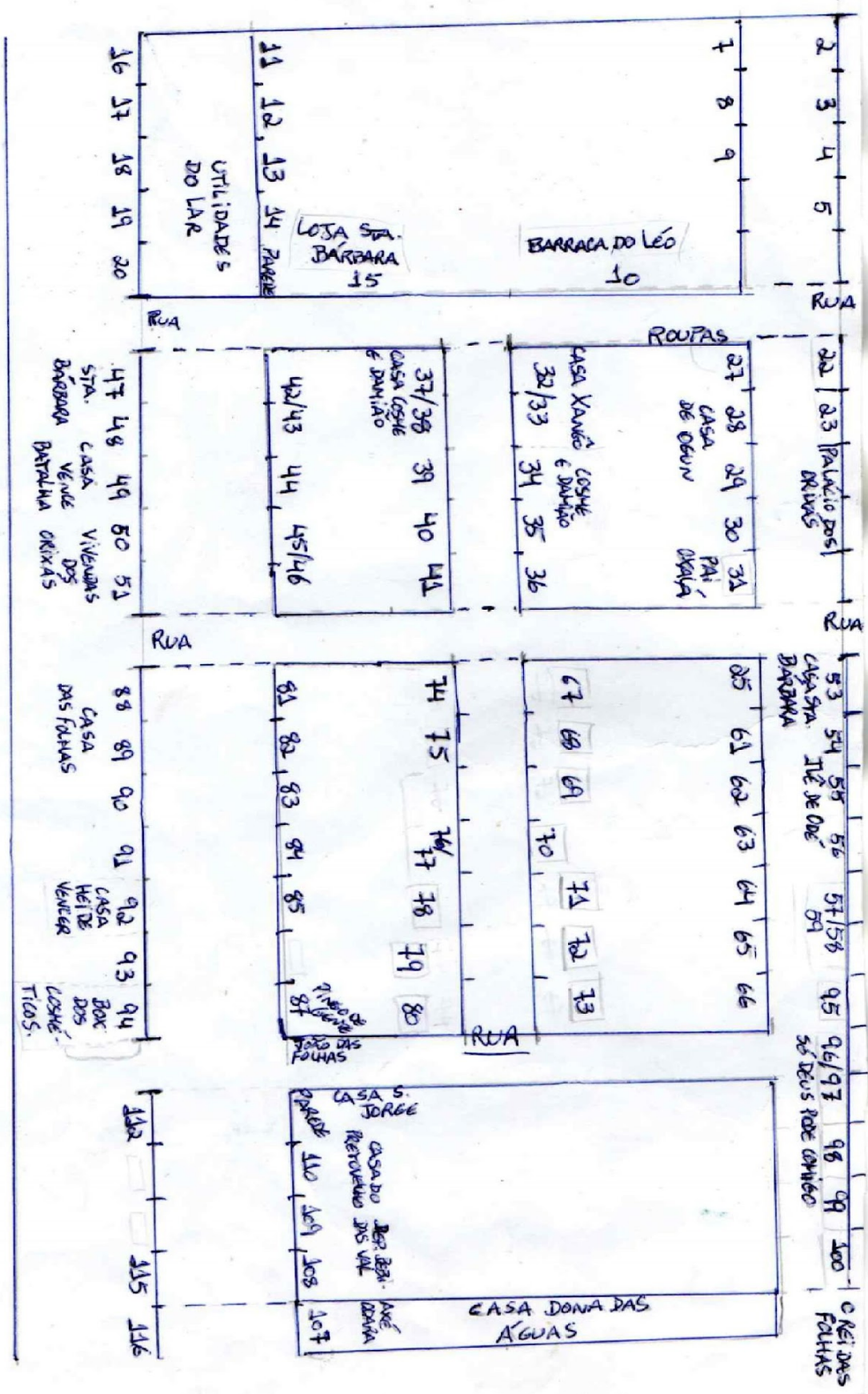

